\title{
CARTOGRAFIA ESCOLAR: DO LIVRO DIDÁTICO À EDUCAÇÃO CARTOGRÁFICA
}

\author{
Rafaela Santos Gonçalves 1 \\ raffaelasg@gmail.com \\ Marcelo Oliveira de Faria 2 \\ marcelo.faria65@gmail.com
}

\author{
PALAVRAS-CHAVE: CARTOGRAFIA, LIVRO DIDÁTICO, ALFABETIZAÇÃO \\ CARTOGRÁFICA; LUGAR.
}

\section{INTRODUÇÃO}

Com a intensificação das mudanças nas últimas décadas do século XX, a geografia, enquanto disciplina escolar, repensa seu papel criando novos conteúdos e métodos e/ou atualizando os já existentes. O final da década de 1970, período marcado por mudanças positivas no cenário da pesquisa e ensino em geografia deu início a uma série de questionamentos em torno do ensino da cartografia e sua inserção no espaço escolar.

É preciso conhecer as dificuldades encontradas pelos alunos na aprendizagem da linguagem cartográfica trabalhada na disciplina de Geografia das escolas de Feira de Santana. Nossa referência teórica para a análise será a alfabetização cartográfica (Simielli:1999) que trabalha a partir do desenvolvimento de competências e habilidades para se formar um "mapeador consciente" e como a cartografia aparece nos livros didáticos.

O objetivo central de nossa proposta foi investigar como os conteúdos cartográficos se apresentam no livro de didático (concepção, conceitos e estratégias de trabalho) e a possível contribuição desses materiais para o desenvolvimento de competências e habilidades propostas pela alfabetização cartográfica.

\section{MATERIAL E MÉTODOS OU METODOLOGIA (ou equivalente)}

Para tanto foi feito levantamento bibliográfico em materiais de referência acerca do ensino da cartografia - concepção, conteúdos e estratégias de trabalho - com especial ênfase na alfabetização cartográfica e suas contribuições para a escola básica.

Em um segundo momento, realizou se uma investigação das propostas do ensino de cartografia nos livros didáticos, com especial ênfase em um trabalho desenvolvido em Londrina PR, a partir de uma perspectiva renovada da cartografia escolar.

Ao final, procuramos apresentar como a cartografia apresentar a idéia da cartografia em uma perspectiva renovada.

\section{RESULTADOS E/OU DISCUSSÃO (ou Análise e discussão dos resultados)}

Com base nas leituras feitas até o presente momento, pudemos entender a cartografia escolar como uma extensão das categorias e linguagem da cartografia oficial, com alguma adaptação (transposição didática) para o universo da escola. Em análise dos livros didáticos pudemos perceber que a cartografia aparece predominantemente como conteúdo, a ser apreendido pelos estudantes, e menos como linguagem que favoreça a leitura e expressão das representações espaciais. Compreendemos que a "educação geográfica" tem na cartografia uma linguagem importante na construção de visões de mundo e, para tanto, advogamos um trabalho que concebe os alunos da escola básica como mapeadores. Um desenhar de seu mundo, o mundo tal qual ele vê.

\footnotetext{
1 Bolsista PROBIC/UEFS, Graduando em Geografia, Universidade Estadual de Feira de Santana; 
Deslocar a cartografia escolar para o campo da linguagem e compreender os estudantes como mapeadores foi o tema central de nosso trabalho que tomou como referência um trabalho desenvolvido em Londrina no Paraná3 no qual os alunos figuram não apenas leitores de mapas, mas como mapeadores do espaço que estão inseridos.

A partir desse novo entendimento da cartografia escolar propomos um trabalho de cartografia escolar a ser desenvolvido na cidade de Feira de Santana - BA com estudantes da escola básica.

\section{CONSIDERAÇÕES FINAIS (ou Conclusão)}

O trabalho discutiu a cartografia existente em alguns livros didáticos, apresentou uma perspectiva renovada a partir de uma experiência desenvolvida em Londrina - PR e buscou apresentar uma proposta de trabalho concebida a partir do entendimento dos estudantes como sujeitos de sua aprendizagem e, portanto, mapeadores de suas experiências espaciais. Apresentar a cartografia em uma perspectiva renovada é sair dos horizontes tradicionais acadêmicos e enxergar a cartografia com outros olhares, presente em diferentes meios científicos, sociais, culturais, ou seja, diversas formas de cartografia.

\section{REFERÊNCIAS}

OLIVEIRA, Aldo Gonçalves de. A Cartografia Escolar e o Ensino de Geografia no Brasil: Um Olhar Histórico e Metodológico a Partir do Livro Didático (1913-1982). João Pessoa-PB, 2010-Abril. Dissertação apresentada ao Programa de Pós-Graduação em Geografia da Universidade Federal da Paraíba (PPGG/UFPB) como requisito parcial para obtenção do título de Mestre em Geografia.

LUNKES, Rudi Pedro. Alfabetização cartográfica: um desafio para o ensino de Geografia. Francisco Beltrão. Unioeste. Disponível em: $<$ http://www.gestaoescolar.diaadia.pr.gov.br/arquivos/File/producoes_pde/artigo_rudi_pedro_ lunkes.pdf $>$. Acesso em: 22 de abril 2015.

MOREIRA, Suely Aparecida Gomes; ULHÔA, Leonardo Moreira. Ensino de Geografia: desafios á prática docente na atualidade. Revista da Católica. Uberlândia, v.1, n.2, p. 69-80. 2009.

FONSECA, Fernanda Padovesi; OLIVEIRA, Jaime Tadeu. A geografia e suas linguagens: o caso da cartografia. In: CARLOS, A. A Geografia na sala de aula. São Paulo: Contexto. p. 62-76.

ALMEIDA, Rosângela Doin de. Do desenho ao mapa. In: Do desenho ao mapa: iniciação cartográfica na escola. 4 ed. São Paulo: Contexto, 2006. p. 99-111.

SEEMANN, J. - Subvertendo a Cartografia Escolar no Brasil. Revista Geografares. Cariri, n. 12, p.138-174, Julho, 2012.

SIMIELLI. M. E. R - Cartografia no ensino fundamental e médio. In, Carlos, A. F. A Geografia na sala de aula. Ed Contexto, São Paulo, 1999.

GRUZINSKI, Serge. A passagem do século: 1480 - 1520: as origens da globalização. São Paulo: Companhia das Letras. 1999.

BRAGA, Marco; GUERRA, Andreia; REIS, José Claudio. Breve história da ciência moderna: vol.2: Das maquinas do mundo ao universo-máquina (séc. XV a XVII). 2 ed. Rio de Janeiro: Jorge Zahar. 2008.

FERNAND, Joly. A cartografia. Campinas, SP: Papirus. 1990.

SEEMANN, Jörn. Carto-Crônicas: Uma viagem pelo mundo da cartografia. Fortaleza: Expressão Gráfica e Editora. 2013.

3 A cidade que ganhou um Atlas. 
ARAUJO, Regina; GUIMARÃES, Raul Borges; RIBEIRO, Wagner Costa. Construindo a Geografia: Uma janela para o mundo. A linguagem dos mapas e a geografia. 2 ed. São Paulo: Moderna. p. 22-43, 2005.

SÍTIOS ARQUEOLÓGICOS DO BRASIL. O sítio arqueológico Xiquexique-Carnaúba dos Dantas. 29 de abril de 2015. Disponível:

$<\underline{\text { http://sitiolanoarquelologia.blogspot.com.br/2015/04/o-sitio-arqueologico- }}$

xiquexique.html>. Acesso em: 24 de Maio 2017.

R7. Pinturas Rupestres. Disponível em: $<$ http://cultura.culturamix.com/historia/pinturas-

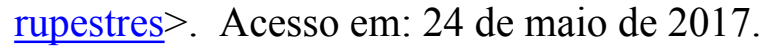

FOTOLA.COM. Ebstorf Mappamundi, 1236 - Tilbury. Disponível em:

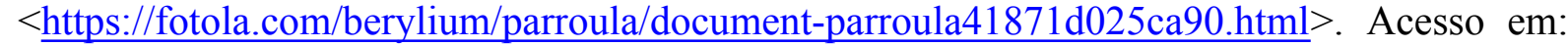
25 de maio de 2017.

TERRA. História da Cartografia. 10 de Fevereiro de 2013. Disponível:

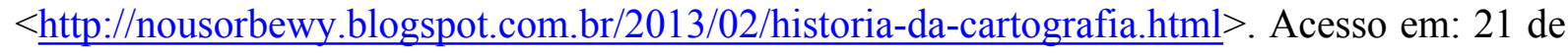
junho de 2017.

ROSSELL, Pere. Cartografía Antigua. 1464. Disponível em: $<$ https://www.pinterest.pt/josemariasaz/cartograf\%C3\%ADa-antigua/>. Acesso em: $21 \mathrm{de}$ junho de 2017.

IBGE，2017. Disponível em: http://atlasescolar.ibge.gov.br/conceitos-gerais/historia-dacartografia/a-era-dos-descobrimentos-sec-xv-a-xviii.html. Acesso em: 22 de junho de 2017.

GURGEL, Abilio Castro. História da Cartografia. A Projeção de Mercator. Disponível em: $<$ http://www.historiadacartografia.com.br/projecao.html $>$. Acesso em 22 de junho de 2017.

LEITE, Carlos; LEVISKY, Adriana. Arch Daily. Masterplan Estratégico para o Centro Antigo de Salvador. Disponível em: http://www.archdaily.com.br/br/624697/masterplanestrategico-para-o-centro-antigo-de-salvador-carlos-leite-e-adriana-levisky. Acesso em: $10 \mathrm{de}$ Junho de 2017.

SALETE MELO. CARTOGRAFIA ARTÍSTICA DO BAIRRO - PROJETO UNICOS E UNOS. 24 de junho de 2009. Disponível em: < http://projetounicoseunos.blogspot.com.br/2009/06/163.html >. Acesso em: 29 de julho de 2017. 